\title{
Assessment of creativity and innovation at a Saudi University
}

Mabrouk Touahmia*, Noureddine Ait-Messaoudene, Mohamed Aichouni, Abdulaziz Al-Ghamdi, Isam Elbadawi, Rashid Al-Hamali, Abdulaziz Al-Ghonamy

College of Engineering, University of Hail, Hail, Saudi Arabia

\section{ARTICLE IN F O}

Article history:

Received 17 December 2016

Received in revised form

1 April 2017

Accepted 2 April 2017

\section{Keywords:}

Creativity

Innovation

Curriculum

Skills

University

\begin{abstract}
A B S T R A C T
Fostering students' creativity and innovation capabilities has always been at the heart of universities' endeavor and engagement. Recognized as a constituting element of knowledge societies, creativity is now considered as a major topic in all fields of the educational systems. This study examines the relevant indicators of creativity and innovation for undergraduate students at the University of Hail and how these indicators can be used to develop creativity and innovation skills among Saudi students. The study is performed through the analysis of the results of a survey that was circulated to students during the occasion of the World Creativity and Innovation Week. The respondents' sample includes 172 students from 10 colleges fairly well distributed among male and female students $(40 / 60 \%)$. Based on the data analysis of the survey, a strong link is perceived to exist between curriculum and creativity and innovation capabilities development. The results reveal that efforts are still needed to raise the awareness of students about the possibilities to enhance and assess their creativity and innovation skills at the university.
\end{abstract}

(C) 2017 The Authors. Published by IASE. This is an open access article under the CC BY-NC-ND license (http://creativecommons.org/licenses/by-nc-nd/4.0/).

\section{Introduction}

Creativity has always been recognized as a constituting element of knowledge and information societies. Nations' success and prosperity depend significantly on the quality of education, creativity and innovation generated by their human resources. For the last two decades, the term creativity has been considered as a central theme in all fields of education in many parts of the world. In many countries, creativity continued to occupy a prominent position in public as well as academic discourses. Skills related to creativity such as "problem solving", "critical thinking", "communication skill" and "collaboration" have occupied an essential place in western educational system (Adams et al., 2009). McWilliam (2009) considered creativity as a key learning outcome in our times, and thus the core business of education. Even in some developing countries, the perception of creativity and innovation advanced considerably to become one of the central issues of the society. Recently, Gulf countries have adopted new strategies and reforms in their educational systems, aiming to

\footnotetext{
* Corresponding Author.

Email Address: m.touahmia@uoh.edu.sa (M. Touahmia) https://doi.org/10.21833/ijaas.2017.05.009

2313-626X/C 2017 The Authors. Published by IASE.

This is an open access article under the CC BY-NC-ND license

(http://creativecommons.org/licenses/by-nc-nd/4.0/)
}

transform their economies from oil-based economies to innovative knowledge-based economies. In Saudi Arabia, higher education infrastructure is expanding considerably fast by establishing new universities, research institutes, innovation and technology centers, and by activating international science, technology and innovation cooperation (Khan et al., 2014; Khorsheed and Al-Fawzan, 2014; Aichouni et al., 2015). Disseminating a culture that encourages creativity and innovation, particularly in science and engineering, has become the centre of Saudi policymakers and educational actors deliberation and aspiration.

However, while the Saudi spending on education exceeds that of many distinguished countries such as Malaysia and Brazil, the impact of education outcomes on Saudi economic performance is still below expectation in comparison to those countries. The quest for innovation and creativity skills enhancement through diverse measures should not go unquestioned though. As an example, Tan and Gopinathan (2000) pose questions about whether various strategies and initiatives that have been employed by the Education Ministry in order to foster creativity and innovation in Singapore were really effective. Although more spending on education does not always lead to greater innovation, low spending on research and development can certainly obstruct both innovation and economic performance (Jaruzelski et al., 2005). 
Sternberg (2006) argued that "Society can play a role in the development of creativity by increasing the rewards and decreasing the costs". Al-Sudairi and Bakry (2014) emphasized the need for building a knowledge national culture that promotes people's drive towards knowledge generation and innovation and towards making efficient utilization of the newer technology. Mayfield and Mayfield (2010) developed a scale to measure workers creative environment perceptions. They concluded that workers' creative output can significantly increase by improving organizations' creative environment. Iqbal (2011) presented an overview of the state of creativity and innovation in Saudi Arabia and discussed the low level of "creative outcomes" reported in the Global Innovative Index (GII). Thus, to succeed in the global innovation game, universities are increasingly expected to provide more opportunities that foster student's cognitive and creative potential. More importantly, they should maintain a relatively high level of research and development spending and demonstrate creativeness and innovativeness in their curricula.

The present study is part of a larger national research project, entitled "Program for Creativity and Innovation Skills Development through Quality and Organizational Excellence Concepts". The project is funded by the Saudi Ministry of Education and aims to provide a better understanding of how creativity and innovation are applied in higher educational practice. The emphasis is on the effectiveness of Saudi universities support policy instruments to promote students' creativity during their learning process. The study takes place at the University of Hail and focuses on undergraduate students.

\section{Research objectives and questions}

The objective of this research is to identify the relevant indicators of creativity and innovation for undergraduate students at the University of Hail and how these indicators can be used to develop creativity and innovation skills among Saudi students. The study is mainly interested to answer the following fundamental questions:

(1)What are the individual characteristics and the personal perceptions of students on their creativity and innovation skills? Do they really believe in their creativity capabilities?

(2) How the education environment affects the creativity and innovation skills among students?

(3)Does the University management support students in their creativity projects?

\section{Research framework}

An extensive literature review on creativity and innovation in the educational field was presented by (Pisanu and Menapace, 2014). Based on the review of the technical literature, they pointed out four main key dimensions to enhance creativity and innovation within organizations and to build a practical framework that can serve as guidelines to a better understanding of the creative process that leads to the stabilization of the innovation within educational systems. The four key elements are identified as: (a) individual characteristics, (b) organizational structures, (c) training methods and pedagogical practices, and (d) training content.

The authors stated that this framework can provide a roadmap to understand and guide the innovation process within organizations. However, in our study, this model is adapted to build the research framework presented in Fig. 1.

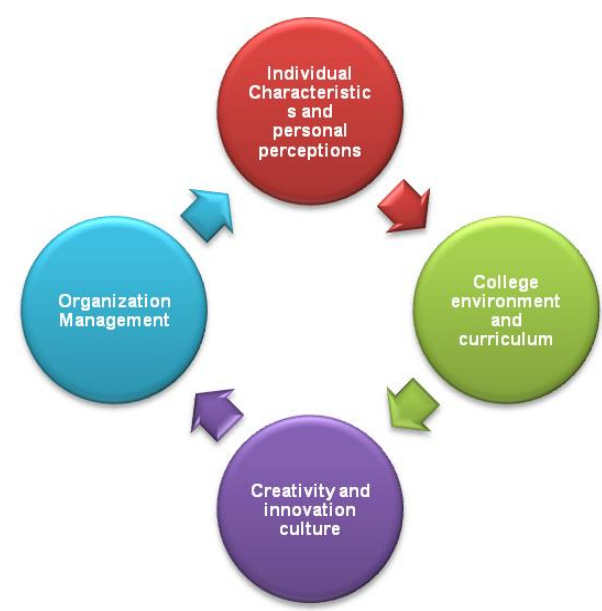

Fig. 1: Research framework

\section{The multifactor questionnaire}

A survey questionnaire was designed with the primary objective to assess the creativity and innovation environment from the perspective of Hail University students, northern area of Saudi Arabia. The design of the survey has undergone different stages and pre-tests which have resulted in eliminating, reclassifying and rephrasing some of the questionnaire elements. The survey uses the fivepoint Lickert's rating scale to measure the different aspects of the subject from the respondent's perspective. This enables eventual comparative deductions since the same scale is used in similar studies. Internal consistency of the elements of the same group of the questionnaire is measured by Cronbach's alpha statistical factor. Values of Cronbach's alpha greater than 0.7 indicate internal consistency of the survey element. Content validity of the survey instrument was examined based on expert's reviews from academic institutions. The survey was administered to the study sample population online using web 2.0 technologies (Google Drive).

The questionnaire comprises 35 items presented in three sections and general questions about the characteristics of the respondent (10 items). Students were first asked about their perceptions of creativity and innovation with regard to their educational system, culture and society. Then, creativity affecting factors were assessed in the college and curriculum, and the opportunities the 
University of Hail would bring to students to foster their creativity and innovation skills. Examples of these items include: "I consider myself as a gifted and talented student" and "The University contributes to spread creativity and innovation culture among students." Items were rated on a 5points scale (1=Strongly Disagree, 2=Disagree, 3=Unsure, 4=Agree and 5=Strongly Agree).

\section{Results and discussion}

\section{1. Consistency analysis}

Internal consistency of the survey is first checked using Cronbach's alpha statistical factor as a standard. This allows being confident that the different groups of questions measure the same concept in the survey. Cronbach's alpha coefficient values higher than 0.7 indicate the questions groupings yield a reliable level of consistency. The calculated coefficients are shown in Table 1, where Cronbach alpha coefficients are in range of 0.78 to 0.88 . These high values of Cronbach alpha indicate that the survey elements can be used reliably and should yield valid results for the purpose of the study.

Table 1: Internal consistency Cronbach's Alpha coefficients for the survey elements

\begin{tabular}{ccc}
\multicolumn{3}{c}{ coefficients for the survey elements } \\
\hline $\begin{array}{c}\text { Sumber of } \\
\text { Questions }\end{array}$ & $\begin{array}{c}\text { Cronbach`s } \\
\text { Alpha }\end{array}$ \\
\hline $\begin{array}{c}\text { Personal Perceptions on } \\
\text { Creativity }\end{array}$ & 15 & 0.805 \\
$\begin{array}{c}\text { University Environment and } \\
\text { Curriculum }\end{array}$ & 10 & 0.781 \\
$\begin{array}{c}\text { University Organizational } \\
\text { Support }\end{array}$ & 10 & 0.881 \\
\hline
\end{tabular}

\section{2. Respondents profile}

The survey was circulated during an event organized at the University and hosted by the faculty of engineering at the occasion of the World Creativity and Innovation Week held from the 19th to 22nd April 2015. Table 2 summarizes the main characteristics of the respondents' profile.

The respondents' sample includes 172 students for a total enrolment of about 32000 students. Although this number might seem modest, it still should reflect the opinion of the students' community as both male and female students (40.1\% male and $59.9 \%$ female) and ten colleges are represented. Respondents are mostly concentrated in Engineering and Education colleges. Actually, the $40 / 60 \%$ male/female distribution fairly corresponds to the 36-51\% distribution for Engineering and Education colleges as all male students are from Engineering and almost all female students are from the college of Literature and Arts. This could be explained by the fact that these two categories were most receptive to communication regarding the survey. This also indicates that more efforts should be dedicated to circulating the information and making students throughout the whole campus respond to any future survey regarding the entire university students' population.

Table 2: Profile of the respondents

\begin{tabular}{|c|c|c|}
\hline Respondents Characteristics & Number & Percentage \\
\hline \multicolumn{3}{|l|}{ Gender } \\
\hline Male & 69 & 40.12 \\
\hline Female & 103 & 59.88 \\
\hline \multicolumn{3}{|c|}{ Level } \\
\hline Preparatory Year & 7 & 4.07 \\
\hline Freshmen & 16 & 9.30 \\
\hline Sophomore & 34 & 19.77 \\
\hline Junior & 54 & 31.40 \\
\hline Senior & 59 & 34.30 \\
\hline Graduate & 2 & 1.16 \\
\hline \multicolumn{3}{|c|}{ Age } \\
\hline$<20$ & 10 & 5.81 \\
\hline $20-25$ & 152 & 88.37 \\
\hline $25-30$ & 8 & 4.65 \\
\hline$>30$ & 2 & 1.16 \\
\hline \multicolumn{3}{|c|}{ College } \\
\hline Engineering & 62 & 36.05 \\
\hline Social Sciences & 1 & 0.58 \\
\hline Literature \&Arts & 88 & 51.16 \\
\hline Education & 8 & 4.65 \\
\hline Science & 1 & 0.58 \\
\hline Preparatory Year & 4 & 2.33 \\
\hline Computer Engineering & 2 & 1.16 \\
\hline Management & 4 & 2.33 \\
\hline Medical Sciences & 2 & 1.16 \\
\hline \multicolumn{3}{|c|}{ English Proficiency } \\
\hline Very Good & 20 & 11.63 \\
\hline Good & 54 & 31.40 \\
\hline Average & 77 & 44.77 \\
\hline Weak & 21 & 12.21 \\
\hline \multicolumn{3}{|c|}{ Internet Use } \\
\hline Not at all & 3 & 1.74 \\
\hline Once a month or less & 11 & 6.40 \\
\hline Once a week or more & 13 & 7.56 \\
\hline Moderate daily use & 81 & 47.09 \\
\hline Intensive daily use & 64 & 37.21 \\
\hline \multicolumn{3}{|c|}{ Parents Educational Level } \\
\hline One or both University graduate & 65 & 37.79 \\
\hline One or both High School graduate & 29 & 16.86 \\
\hline $\begin{array}{l}\text { One or both Junior High School } \\
\text { graduate }\end{array}$ & 23 & 13.37 \\
\hline $\begin{array}{c}\text { One or both Elementary School } \\
\text { graduate }\end{array}$ & 30 & 17.44 \\
\hline One or both illiterate & 25 & 14.53 \\
\hline \multicolumn{3}{|c|}{ Family Financial Situation } \\
\hline$<3000 \mathrm{SAR} /$ month & 24 & 13.95 \\
\hline 3000-6000 SAR/month & 35 & 20.35 \\
\hline 6000-10 000 SAR/month & 47 & 27.33 \\
\hline $10000-20000 \mathrm{SAR} / \mathrm{month}$ & 51 & 29.65 \\
\hline$>20000 \mathrm{SAR} /$ month & 15 & 8.72 \\
\hline
\end{tabular}

Moreover, $88.4 \%$ of the respondents are in the age group of 20 to 25 , which is representative of the actual student population. It should nevertheless be noted that most of the respondents are from the College of Literature and Arts with $51 \%$ followed by the College of Engineering with 36\% and the College of Education with 5\%. In reality, the College of Education is well ahead of the Engineering College in terms of students' enrolment. This could be explained by the fact that the College of Engineering is the main organizer of the Innovation and creativity week that was held during April 2015 and during which the survey was circulated. On the other hand, $85 \%$ of the respondents are freshmen and upper with a predominance of junior and senior (65\%). This should be more indicative of students experience in the university as the sample 
represents students with enough background about university practices. The respondents' academic profile also exhibits an average to good English level with $76 \%$ of the respondents considering themselves to be in that range, keeping in mind that English is a foreign language for Saudi students, with a fairly high level of internet use with $84 \%$ showing normal to extensive daily use. The family profile of the students' sample is within the university to high school with $55 \%$ and junior high to elementary school with $31 \%$. The family income level is within the upper middle level with $27 \%$ in the $6000-10000$ SAR/month, $39 \%$ above and $34 \%$ below.

\subsection{Students' personal attitude toward creativity and innovation}

Students' personal attitude regarding creativity and innovation is measured through a series of 15 questions presented in Table 3 and Fig. 2. This part of the questionnaire includes items referring to values that reflect creativity according to Aichouni et al. (2015). Self-perceptions of creativity are also included in this part of the questionnaire to gain some information but not as specific criteria for measuring creativity abilities as this issue should be handled with caution (Reiter-Palmon et al., 2012).

The degree of approval of the propositions expressed by the different questions can be evaluated through the cumulated percent scores for "strongly agree" and "agree" responses. Questions scoring above $90 \%$ are Q3, Q6 and Q9 indicating that the vast majority of students consider that creativity and innovation can be developed, that they require risk taking experimentation as well as family support.

Table 3: Questionnaire regarding personal attitude towards creativity and innovation

\begin{tabular}{|c|c|}
\hline Q\# & Question \\
\hline Q1 & I consider myself as a creative and talented student \\
\hline Q2 & $\begin{array}{c}\text { I am regularly engaged in creative and innovative } \\
\text { type of work }\end{array}$ \\
\hline Q3 & $\begin{array}{c}\text { Creativity can be conceptualized as skills that can be } \\
\text { developed }\end{array}$ \\
\hline Q4 & $\begin{array}{l}\text { Creativity requires experience and knowledge more } \\
\text { than intelligence }\end{array}$ \\
\hline Q5 & $\begin{array}{l}\text { Quality management tools positively contribute to } \\
\text { innovation performance }\end{array}$ \\
\hline Q6 & $\begin{array}{l}\text { Creativity and innovation require risk-taking and } \\
\text { freedom for experimentation }\end{array}$ \\
\hline Q7 & $\begin{array}{l}\text { Creativity and innovation require close links with } \\
\text { working professionals }\end{array}$ \\
\hline Q8 & $\begin{array}{l}\text { Societal recognition is the key element to enabling } \\
\text { and sustaining creativity and innovation }\end{array}$ \\
\hline Q9 & Creative student needs family encouragement \\
\hline Q10 & $\begin{array}{c}\text { IT plays an essential role in stimulating creativity and } \\
\text { innovation }\end{array}$ \\
\hline Q11 & Creative student prefers team work interaction \\
\hline Q12 & $\begin{array}{c}\text { Creative student is highly self-motivated and } \\
\text { confident }\end{array}$ \\
\hline Q13 & $\begin{array}{l}\text { Creative student strives for high standards of } \\
\text { personal achievement }\end{array}$ \\
\hline Q14 & $\begin{array}{c}\text { Creativity and innovation can play an important role } \\
\text { in the knowledge society }\end{array}$ \\
\hline Q15 & $\begin{array}{l}\text { Creativity and innovation are important for driving } \\
\text { countries' social and economic growth }\end{array}$ \\
\hline
\end{tabular}

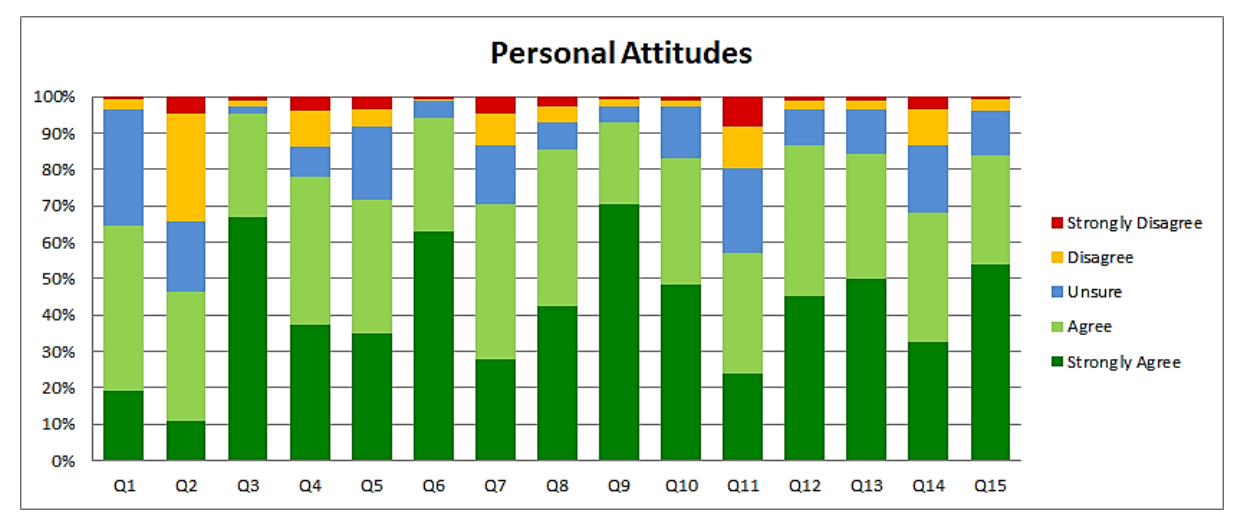

Fig. 2: Students' personal attitude towards creativity and innovation ( $n=172, M=4.11, S D=0.94)$

This is consistent with findings of Fleith (2000) suggesting that both teachers and students believe that a classroom environment which students with choices, accepts different ideas enhances creativity abilities. Questions yielding a score of above $80 \%$ to around $87 \%$ are Q8, Q10, Q12, Q13 and Q15. This indicates that societal recognition, IT, selfmotivation, striving for high standards of achievement and contribution to country's social and economic growth are considered of great importance but not among key elements fostering creativity and innovation. This is more evident when singling out the "strongly agree" scores which stand at less than average values ranging from $40 \%$ to $50 \%$. Questions with lower scores of around 70 to less than $80 \%$ are Q4, Q5, Q7 and Q14. This indicates that the respondents do unequivocally agree with the fact that creativity requires more experience than knowledge, importance of quality tools, importance of links with professionals, preference of teamwork and role in developing a knowledge society. Questions with the lowest scores of less than 65\% are Q1, Q2 and Q11 in conformity with the fact that the survey has not specifically targeted students regularly engaged in innovation and creativity activities but also indicating that creativity and innovation do not seem to be among the priorities of students. The result of question 11 is somewhat unexpected as it indicates that teamwork is not considered of importance by the students' sample. This clearly contrasts with the findings of the study mentioned previously with a $73 \%$ score and close to 
$50 \%$ "strongly agree" score whereas this latter stands just at above $20 \%$ for this question.

The conclusion that can be drawn from this part of the survey is that efforts need to be performed to raise the level of engagement in creativity and innovation activities and the level of awareness about the importance of some elements in fostering creativity and innovation such as team work and self-motivation. Students should also be more motivated by the role of creativity and innovation in the country's economic development as they do not seem to be aware about this aspect. On the other hand, the fact that social recognition is not considered a key driving motivation can be considered as positive since self-satisfaction is more readily achievable and a stronger incentive.

\subsection{Students' perception of creativity and innovation in the curriculum}

This part deals with the perception of the students' sample about how creativity and innovation skills relate to academic curricula. Kazerounian and Foley (2007) have formalized what they called "The Ten Maxims of Creativity in Education". This is a proposed set of ten factors that constitute and foster a creative educational paradigm. But their focus is on the detailed curriculum content per se. In the present study, it is more the perception of students on how the curriculum globally relate to creativity and innovation which is investigated. Ferrari et al. (2009) have proposed a set of 'enablers' that allow creative learning and innovative teaching to emerge, and thus facilitate creativity and innovation. These are: assessment; culture; curriculum; individual skills; teaching and learning format; teachers; technology; and tools. They also affirm that evaluation of creativity needs to take into account both students' and teachers' perspectives. Bocconi et al. (2012) have demonstrated that the educational system has a strong influence on creativity and innovation. The economic implication is also of importance as Hamidi et al. (2008) found that students engaged in academic entrepreneurship programs had higher intentions to start their own businesses in the future. The present result confirm this finding as there is a strong agreement among the students' sample that all aspects regarding curriculum content addressed by the survey questions shown in Table 4 can enhance creativity and innovation skills. The mean of the responses according to Lickert scale is 4.02, which corresponds to agreement with the proposed expression. The cumulated "agree" and "strongly agree" proportion of responses is around to well above 70\%; except for Q7 and Q10 with respectively around 60\% and 45\% , the lowest value. For question 7 , it could be explained by the fact that interdisciplinary learning is not well apprehended by students at this level. For question 10, its formulation deals with effects of graduate studies that cannot be grasped by undergraduate students as only two respondents among the 172 are graduate students. This can also explain the relatively modest level of agreement with expression Q9. Yet, the less than 70\% score for cumulated "agree" to "strongly agree" for Q1 is somewhat unexpected when compared to the other questions in this part of the questionnaire. This results reveals that efforts are still needed to raise the awareness of students about the possibility to enhance and assess creativity and innovation skills at the university.

The results of this part are in fairly good agreement with a previous study targeting elementary to high school gifted students with a mean value of $3.95(\mathrm{SD}=1.13)$ compared to 4.02 for the present study. This indicates globally the same level of perception about importance of the link between curriculum and creativity and innovation activities.

Table 4: Questionnaire regarding students' perception of creativity and innovation in the curriculum

\begin{tabular}{cc}
\hline Q\# & Question \\
\hline Q1 & $\begin{array}{c}\text { Creativity skills can be learned and assessed at higher } \\
\text { education level }\end{array}$ \\
Q2 & $\begin{array}{c}\text { Creative learning can foster students' creativity and } \\
\text { innovations }\end{array}$ \\
Q3 & $\begin{array}{c}\text { Innovative teaching methods can develop students' } \\
\text { creative thinking }\end{array}$ \\
Q4 & $\begin{array}{c}\text { Creative and innovation activities can improve } \\
\text { students' academic achievements }\end{array}$ \\
Q5 & $\begin{array}{c}\text { Integrating creative courses into the curriculum can } \\
\text { enhance students' creative capacities }\end{array}$ \\
Q6 & $\begin{array}{c}\text { Creative training programs can develop students' } \\
\text { creative thinking and innovation abilities }\end{array}$ \\
Q7 & $\begin{array}{c}\text { Interdisciplinary learning can promote students' } \\
\text { creativity and innovation capacities }\end{array}$ \\
Q8 & $\begin{array}{c}\text { Problem and project based learning can develop } \\
\text { students' creative capabilities }\end{array}$ \\
Q9 & $\begin{array}{c}\text { Graduate studies and research stimulate innovation } \\
\text { Graduate education system is creative enough to } \\
\text { Q10 }\end{array}$ \\
& adapt students to changing labor market
\end{tabular}

As discussed by Bocconi et al. (2012), there is a causal relationship between creativity, innovation and the education system. Educational organizations, from primary to higher education, are considered to be optimal environments for enabling experiences of innovation that learners can transfer to real-life settings through innovative and creative projects. Fasko (2001) discussed the relation of education to creativity in students of preschool age through age 16 in U.S. public schools. He emphasized the need for creativity courses in teacher education programs. The present results show an agreement between students on the fact that their educational environment, including teachers, schools and the curriculum, contributes positively in fostering their innovative and creativity skills $(\mathrm{M}=3.95, \mathrm{SD}=1.13)$. Some discrepancy can be observed from the higher standard deviation within this survey element $(S D=1.13)$. The lowest value was recorded for the question "Students in my college recognize the importance of innovation and creativity" where only $38 \%$ agreed on that statement (Fig. 3). This indicates that there is lack of awareness on innovation and creativity among school students; this observation 
was also made by Al-Qarni (2010), Iqbal (2011) and Alamer (2014) in the Saudi educational context.

\subsection{Students' perception about university organizational support}

In this part, the organizational support provided by the university to creativity and innovation related activities as seen by the student is analyzed through the results of a set of ten questions and presented in Fig. 4. The importance of organizational support has been demonstrated in previous studies as there is a two-way influence between the individual and the organization (Amabile, 1988).

The questions presented in Table 5 can be divided in two parts. Q1 to Q6 and Q10 relate to "what is" or to the assessment of actual practices. Whereas Q7, Q8 and Q9 relate to "what could be" or to assessment of practices that, if established, could enhance creativity and innovation.

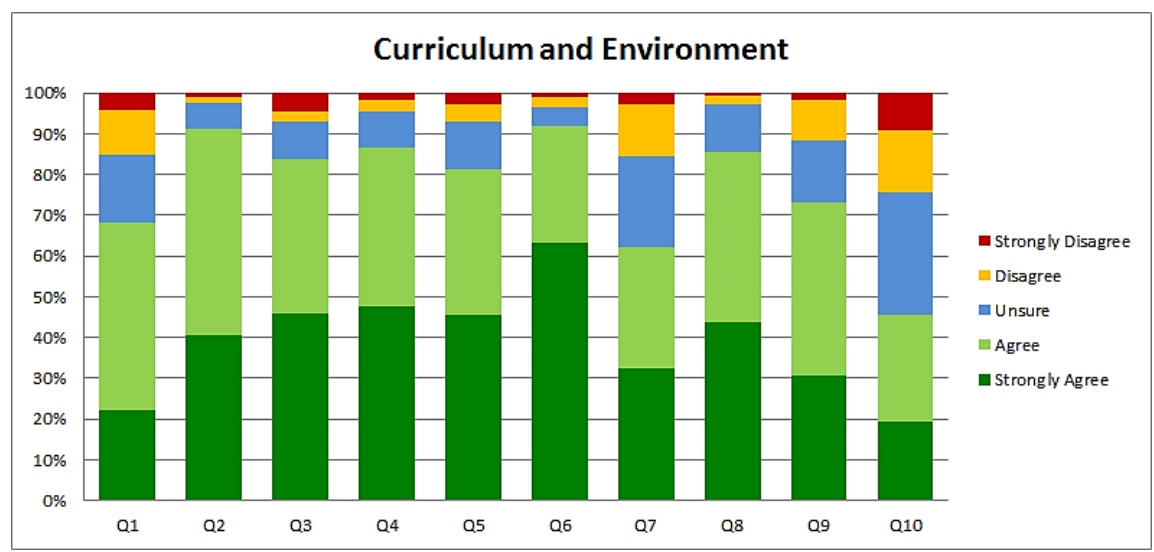

Fig. 3: Students perception of creativity and innovation in the curriculum ( $n=144, M=4.02, S D=0.96)$

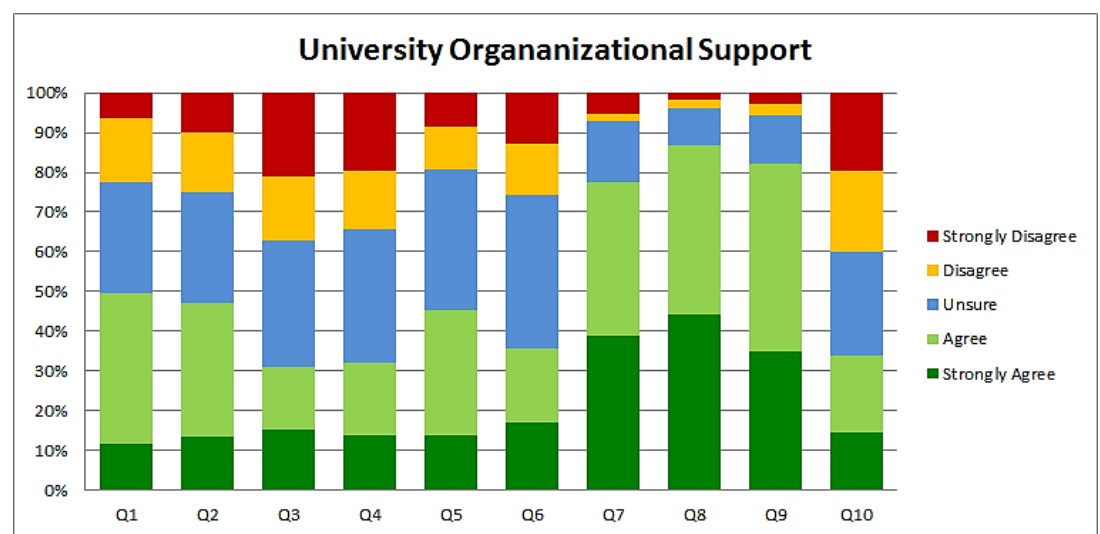

Fig. 4: Students perception of university's support in fostering creativity and innovation ( $\mathrm{n}=172, \mathrm{M}=3.44, \mathrm{SD}=1.19)$

Table 5: Questionnaire regarding students' perception of university support to creativity and innovation activities

\begin{tabular}{|c|c|}
\hline Q\# & Question \\
\hline Q1 & $\begin{array}{c}\text { The university engages students in creative and } \\
\text { innovative activities }\end{array}$ \\
\hline Q2 & $\begin{array}{c}\text { The university offers assistance and training } \\
\text { programs for students engaged in creative and } \\
\text { innovative works }\end{array}$ \\
\hline Q3 & $\begin{array}{l}\text { The university provides creative spaces where } \\
\text { students can innovate }\end{array}$ \\
\hline Q4 & $\begin{array}{l}\text { The university provides a safe environment for } \\
\text { experimentation and risk-taking for students }\end{array}$ \\
\hline Q5 & $\begin{array}{l}\text { The university assesses students' creative and } \\
\text { innovative works }\end{array}$ \\
\hline Q6 & $\begin{array}{l}\text { The university supports materially students } \\
\text { engaged in creative activities }\end{array}$ \\
\hline Q7 & $\begin{array}{l}\text { Establishing a center for creative learning can } \\
\text { promote the culture of innovation }\end{array}$ \\
\hline Q8 & $\begin{array}{l}\text { Building more explicit culture of recognition for } \\
\text { creative students can promote innovation }\end{array}$ \\
\hline Q9 & $\begin{array}{l}\text { Creating and innovative culture is significantly } \\
\text { affected by the learning culture }\end{array}$ \\
\hline Q10 & $\begin{array}{l}\text { The university provides adequate support that help } \\
\text { students develop their innovative and creative skills }\end{array}$ \\
\hline
\end{tabular}

The first results that draws the attention is the significantly lower mean for this part of the questionnaire compared to the previous one (regarding curriculum content) with $3.44(\mathrm{SD}=0.96)$ compared to 4.02; meaning that overall, the students' sample considers that there is not sufficient support from the university to creativity and innovation activities. This is even more obvious if results of Q1-Q6 and Q10, specifically addressing this issue as mentioned above, are taken separately. Indeed, the mean of the results for these seven questions falls to $3.14(\mathrm{SD}=1.22)$ indicating a clear "disagree" evaluation according to Lickert scale. On the other hand, the mean for Q6, Q7 and Q8 stands at 4.12 ( $\mathrm{SD}=0.94)$, indicating that the students of the sample think that taking initiatives such as establishing a centre for creative learning and a culture of recognition or properly addressing the learning culture itself can promote creativity and innovation. In this part and in contrast with the previous one, the cumulated "strongly agree" to 
"agree" scores are in the relatively low range of 30\% to $50 \%$ for Q1-Q6 and Q10; whereas they stand in a much higher range of $77 \%$ to $86 \%$, again confirming the observations mentioned above. The lowest scores, around 30\%, are for questions Q3, Q4, Q6 and Q10 addressing the basic issue of providing space and material support for creativity and innovation activities. These results should be regarded as indicative of opportunities to improve the environment for fostering students' creativity and innovation within the university. It seems that one of the first steps would be to create clearly defined and dedicated structures beneficiating from adequate material support for creativity and innovation activities.

These observations are considered by the research team to be an opportunity to focus on providing training and awareness program to students especially in creativity and innovation tools and techniques such as those described by the American society of Quality in the reference book by Keathly et al. (2013). It is worth mentioning here that, as pointed out recently by (Pisanu and Menapace, 2014), the use of creative thinking techniques such as brainstorming, lateral thinking, mind-mapping, six thinking hats technique, morphological analysis, can improve substantially the existing levels of creativity and innovation among individuals in organizations, including higher education institutions.

\section{Conclusion}

The present study aims at assessing students' perception on creativity and innovation activities in the University of Hail (Kingdom of Saudi Arabia). The study is performed through the analysis of the results of a survey that was circulated during the World Creativity and Innovation Week event held at the University of Hail from 19 to 22 April 2015. The respondents' sample includes 172 students fairly well distributed among male and female students (40/60\%) and representing ten colleges with a predominance of the colleges of Literature and Arts and Engineering. Based on the results of the survey, the following main conclusions can be formulated:

- Efforts need to be performed to raise the level of engagement in creativity and innovation activities and the level of awareness about the importance of some elements in fostering creativity and innovation such as team work and self-motivation. Students should also be more motivated by the role of creativity and innovation in the country's economic development.

- A strong link is perceived to exist between curriculum and creativity and innovation activities. Therefore, a great deal of importance should be granted to including material that can contribute to fostering creativity and innovation among students in academic curricula.
- Efforts are still needed to raise the awareness of students about the possibilities to enhance and assess creativity and innovation skills at the university.

- Organizational support is perceived as insufficient and addressing basic issues such as providing space and material support for creativity and innovation activities is yet perceived inadequately. A clear gap is revealed regarding this aspect when comparing with the situation of elementary to high school levels where a support organization is set through the "Gifted Students Administration". This is termed as the "weak link" by the authors.

- The results of the last part of the study regarding organizational support should be regarded as indicative of opportunities to improve the educational environment for fostering students' creativity and innovation within the university through well designed strategies and programs. Taking initiatives such as establishing a center for creative learning and a culture of recognition or properly addressing the learning culture itself can promote creativity and innovation.

\section{Acknowledgment}

This study was supported by the Saudi Ministry of Education under the framework of the National Initiative on Creativity and Innovation in Saudi Universities. The authors gratefully acknowledge the support of their research program.

\section{References}

Adams J, Kaczmarczyk S, Picton P, and Demian P (2009). Problem solving and creativity in Engineering: turning novices into professionals. Enhancing the Learner Experience in Higher Education, 1(1): 4-18.

Aichouni M, Touahmia M, Al-Ghamdi A, Ait-Messaoudene N, AlHamali RM, Al-Ghonamy A, and Al-Badawi E (2015). Creativity and Innovation among gifted Saudi students-an empirical study. Procedia - Social and Behavioral Sciences, 195: 13711379.

Alamer SM (2014). Challenges facing gifted students in Saudi Arabia. Research on Humanities and Social Sciences, 4(24): 107-112.

Al-Qarni MA (2010). Evaluation of provisions for gifted students in Saudi Arabia. Ph.D. Dissertation, University of Wollongong, Wollongong, Australia.

Al-Sudairi M and Bakry SH (2014). Knowledge issues in global innovation index: Assessment of the state of Saudi Arabia versus countries with distinct development. Innovation: Management, Policy \& Practice, 16(2): 176-183.

Amabile TM and Teresa M (1988). A model of creativity and innovation in organizations. Research in Organizational Behavior, 10(1): 123-167.

Bocconi S, Kampylis P, Punie Y (2012). Innovating learning: key elements for developing creative classrooms in Europe. European Commission, Joint Research Centre - Institute for Prospective Technological Studies, Seville, Spain. Available online at: ftp://s-jrcsvqpx101p.jrc.es/pub/EURdoc/EURdoc/ JRC72278.pdf

Fasko D (2001). Education and creativity. Creativity Research Journal, 13(3-4): 317-327. 
Ferrari A, Cachia R, and Punie Y (2009). Innovation and creativity in education and training in the EU member states: Fostering creative learning and supporting innovative teaching. JRC Technical Note, No. 52374. Literature Review on Innovation and Creativity in E\&T in the EU Member States (ICEAC), Office for Official Publications of the European Communities, Luxembourg, Luxembourg. Available online at: ftp://ftp.jrc.es/users/publications/public/EURdoc/JRC52374 _TN.pdf

Fleith DS (2000). Teacher and student perceptions of creativity in the classroom environment. Roeper Review 22(3): 148-153.

Hamidi DY, Wennberg K, and Berglund H (2008). Creativity in entrepreneurship education. Journal of Small Business and Enterprise Development, 15(2): 304-320.

Iqbal A (2011). Creativity and innovation in Saudi Arabia: An Overview. Innovation: Management, Policy and Practice, 13(3): 376-390

Jaruzelski B, Dehoff K, and Bordia R (2005). Money isn't everything. Strategy + Business, 41: 54-67.

Kazerounian K and Foley S (2007). Barriers to creativity in engineering education: A study of instructors and students perceptions. Journal of Mechanical Design, 129(7): 761-768.

Keathly J, Merrill P, Owens T, Meggarrey I, and Posey K (2013). The executive guide to innovation: turning good ideas into great results. ASQ Quality Press, Milwaukee, USA.

Khan MK, Al-Saud T, Alkhathlani H, and Al-Derham H (2014). New reforms of research, innovation and entrepreneurship in the
GCC countries. Management, Policy and Practice, 16(2): 174175.

Khorsheed M and Al-Fawzan MA (2014). Fostering universityindustry collaboration in Saudi Arabia through technology innovation centers. Management, Policy and Practice, 16(2): 224-237.

Mayfield M and Mayfield J (2010). Developing a scale to measure the creative environment perceptions: A questionnaire for investigating garden variety creativity. Creativity Research Journal, 22(2): 162-169.

McWilliam E (2009). Teaching for creativity: from sage to guide to meddler. Asia Pacific Journal of Education, 29(3): 281-293.

Pisanu F and Menapace F (2014). Creativity and innovation: Four key issues from a literature review. Creative Education, 5(3): $145-154$.

Reiter-Palmon R, Robinson-Morral EJ, Kaufman JC, and Santo JB (2012). Evaluation of self-perceptions of creativity: Is it a useful criterion?. Creativity Research Journal, 24(2-3): 107114.

Sternberg RJ (2006). The nature of creativity. Creativity Research Journal, 18(1): 87-98

Tan J and Gopinathan S (2000). Education reform in Singapore: Towards greater creativity and innovation. NIRA Review, 7(3): 5-10. 